\title{
Framework Conceitual de apoio ao Design de Ambientes Colaborativos inclusivos aos Surdos
}

\author{
Daniela de Freitas Guilhermino Trindade ${ }^{1,2}$, Laura Sanchez Garcia ${ }^{2}$ \\ ${ }^{1}$ Centro de Ciências Tecnológicas - Universidade Estadual do Norte do Paraná (UENP) \\ Campus Luiz Meneghel, Bandeirantes, Pr - Brasil \\ ${ }^{2}$ Departamento de Informática - Universidade Federal do Paraná (UFPR) \\ Curitiba, Pr - Brasil \\ danielaf@uenp.edu.br, laura@inf.ufpr.br
}

\begin{abstract}
It is important that Computer Science research be based on the needs and specificities of the people, in order to inform design and to deliver tools to mitigate the communication barriers and to promote knowledge access and social inclusion. This article studies the knowledge creation process of a Community of Practice (CoP) of non-deaf and Deaf members around the domain of Libras (Brazilian Sign Language). The observations allowed to determine some requirements, that are compiled and presented here as a Conceptual Framework to inform design of Inclusive Collaborative Virtual Environments (ICVE) to be used to cultivate CoP for Deaf inclusion.
\end{abstract}

Resumo. É importante que pesquisas em Ciência da Computação atentem para as necessidades e especificidades das pessoas, a fim de orientar o projeto de ferramentas para minimizar as barreiras de comunicação, promover o acesso ao conhecimento e a inclusão social. Este artigo estuda o processo de criação do conhecimento em uma Comunidade de Prática (CoP) em torno do domínio da Libras (Língua Brasileira de Sinais) formada por surdos e não-surdos. As observações permitiram determinar alguns requisitos, que foram compilados $e$ apresentados como um Framework Conceitual para apoiar o design de Ambientes Colaborativos Virtuais de cultivo à CoP inclusivos aos surdos.

\section{Introdução}

As comunidades surdas vivem um momento histórico de luta pela afirmação de seus direitos sociais, que lhes foram negados por muitos anos. Para Fernandes (2006, p.1), "entre suas reivindicações mais importantes, figura o direito à utilização das línguas de sinais nos diferentes contextos de interação social e de acesso ao conhecimento".

No Brasil, assim como em todos os países, a linguagem falada/oral é a dominante e, para os surdos, acaba sendo muito difícil usá-la como única opção para estabelecer as relações pessoais. A identidade cultural dos surdos apresenta características que se traduzem de forma visual, pois sua forma de ver o mundo está intimamente ligada às experiências visuais (Quadros, 2007). Assim, conhecer as necessidades desta comunidade e oferecer ferramentas de apoio adequadas, constituem passos importantes para a sua inclusão na sociedade, em respeito aos seus direitos de cidadãos. Segundo Mantoan (2005), "inclusão é a nossa capacidade de entender e reconhecer o outro e, assim, ter o privilégio de conviver e compartilhar com pessoas diferentes...”. 
Com intuito de garantir a inclusão devem ser asseguradas às pessoas as condições apropriadas de atendimento às peculiaridades individuais, para que possam usufruir das oportunidades existentes. As interações por meio de atividades colaborativas mediadas pelo computador têm relevância para a formação humana, social, histórica, política, e podem contribuir para a construção do conhecimento e da identidade do surdo. Neste sentido, Comunidades de Prática (CoPs), conceito que emergiu das áreas de Trabalho Cooperativo Suportado por Computador (Computer Supported Cooperative Work $\mathrm{CSCW}$ ) e Aprendizagem Cooperativa Suportada por Computador (Computer Supported Cooperative Learning - CSCL), podem representar estes ambientes, espaços democráticos e heterogêneos para proporcionar acesso à informação, compartilhar experiências, construir conhecimento, conversar e compreender a realidade de outras pessoas que atuam ou têm interesses em um domínio comum. Entretanto, Almeida e Baranauskas (2008) relatam que ainda existem muitas "lacunas" em frameworks para CSCW e CSCL em relação aos aspectos físicos, empíricos e sociais.

No presente trabalho, foram analisados alguns ambientes virtuais colaborativos projetados e desenvolvidos especialmente para os surdos. Estes ambientes ainda apresentam algumas limitações, dentre elas: considerar um conjunto estático de sinais; utilizar vídeos pré-definidos para disponibilizar informação e conteúdos em Libras (língua natural dos surdos brasileiros), dificultando a interatividade e "engessando" o compartilhamento da informação; apresentar o uso exclusivo do alfabeto manual e de soletração, o que não traduz a essência da Libras; desconsiderar outras necessidades de informação que podem contribuir para a aprendizagem, pelo surdo.

Neste contexto, buscou-se identificar as especificidades necessárias à garantia de acessibilidade para os surdos em ambientes mistos (surdos e não-surdos). Com este intuito, foi criada e cultivada uma CoP por meio de reuniões colaborativas, de forma a fornecer um ambiente de interação que permitisse aos seus participantes colaborarem em prol de um objetivo comum. A partir dessa investigação e de alguns modelos de colaboração e aprendizagem, foi proposto um framework conceitual para apoiar o design de ambientes colaborativos de cultivo à CoP inclusivos aos surdos, denominado FC_InCoP, buscando dar mais um passo em direção à criação de ambientes computacionais acessíveis e inclusivos de apoio à construção social do conhecimento.

Este artigo está organizado da seguinte forma: na seção 2 é apresentada uma discussão a respeito de algumas teorias envolvidas nesta pesquisa; a seção 3 traz os passos metodológicos empregados no trabalho; na seção 4 é apresentado o estudo etnográfico realizado junto à comunidade surda; a seção 5 apresenta o $\mathrm{FC} \_$InCoP. Finalmente, na seção 6 são descritas as conclusões da pesquisa.

\section{Comunidades de Prática, Espaços de Colaboração e de Construção do Conhecimento}

A construção do conhecimento requer uma nova cultura de trabalho que Lave and Wenger (1991) denominaram "Comunidade de Prática". Comunidade de Prática é definida por Wenger et al. (2011) como um grupo de pessoas que compartilham um interesse ou paixão por algum tema e que buscam interagir regularmente para melhorar o seu conhecimento sobre o mesmo. A construção do conhecimento ocorre durante a colaboração dentro das CoPs, pela troca de experiências, pela observação e assimilação das habilidades específicas intrínsecas a cada participante, pela troca de ideias para a 
tomada de decisões e para a resolução de problemas.

Natalli e Menezes (2010) relatam que a colaboração permite que pessoas com diferentes competências realizem tarefas interdependentes, as quais o debate e o refinamento de ideias são essenciais para o sucesso na tomada de decisão. Em uma CoP, a interação ocorre em um processo de interação dinâmica entre os seus membros, que trocam informações, conhecimentos e comportamentos (Schneider et al., 2012).

Um trabalho robusto de investigação que contribui com um arcabouço conceitual para a melhoria da aprendizagem colaborativa foi realizado por Tifous et al. (2007). Os conceitos relacionados na ontologia foram definidos a partir de uma investigação em 12 CoPs do projeto Palette (http://palette.ercim.org/) (Henri, 2006). O Quadro 1 apresenta uma síntese, feita pela autora do presente trabalho, a partir dos resultados da investigação desses autores.

Quadro 1. Principais conceitos inerentes às CoPs

\begin{tabular}{|c|c|c|}
\hline \multicolumn{2}{|r|}{ CoP - Principais Conceitos } & Autores \\
\hline \multirow{3}{*}{ Comunidade } & Motivação; Domínio; Prática & Wenger (2004) \\
\hline & Campo; Objetivo; Estrutura; Composição & Tifous et al. (2007) \\
\hline & Diversidade cultural & Langelier (2005) \\
\hline Membros & $\begin{array}{l}\text { Características pessoais; Tipo de envolvimento; } \\
\text { Papel na CoP; Papel periférico }\end{array}$ & $\begin{array}{c}\text { Miller (1995), } \\
\text { Tifous et al. (2007) }\end{array}$ \\
\hline Competência & Tipo de competência & Tifous et al. (2007) \\
\hline \multirow[t]{2}{*}{ Colaboração } & $\begin{array}{l}\text { Objetivo da colaboração; Atividades colaborativas; } \\
\text { Papéis envolvidos; Dimensão geográfica; Dimensão } \\
\text { temporal; Recursos da colaboração; Meios de } \\
\text { comunicação; Tipos de interação }\end{array}$ & Vidou et al. (2006) \\
\hline & Engajamento; Coordenação & $\begin{array}{l}\text { Deaudelin et al. (2003), } \\
\text { Weiseth et al. (2006) }\end{array}$ \\
\hline $\begin{array}{l}\text { Tomada de } \\
\text { Decisões }\end{array}$ & $\begin{array}{l}\text { Recursos para a tomada de decisões; Resultado; } \\
\text { Atores envolvidos; Estratégias }\end{array}$ & \multirow[t]{2}{*}{ Tifous et al. (2007) } \\
\hline Recursos da coP & Registro de interações; Ferramentas da CoP & \\
\hline
\end{tabular}

Uma CoP envolve uma série de elementos e as suas inter-relações necessárias ao alcance dos objetivos. A abordagem de Tifous et al.( 2007) apresenta os principais elementos, com a sua semântica, que podem, dentre outros contextos de CSCW, ser usados em ferramentas de apoio à construção do conhecimento nas CoPs. A construção do conhecimento é um processo social contínuo de clarificação de objetivos que negocia o comprometimento e encoraja o aprendizado mútuo e o desenvolvimento de habilidades (Carroll et al. 2003). O conhecimento é caracterizado como um conjunto de itens de informação contextualizada e dotada de significados inerentes ao agente que o detém (Santana e Santos, 2002).

A troca de informação pode ocorrer de forma tácita ou explícita. Takeuchi e Nonaka (2008) descrevem que o conhecimento tácito é relacionado às experiências particulares de cada um, às suas habilidades, crenças e situações vividas no cotidiano; já o conhecimento explícito diz respeito a regras gramaticais, textos, manuais, gráficos, planilhas e demais tipos de documentos que têm registro e podem ser compartilhados. $\mathrm{O}$ processo de transformação envolvendo conhecimentos tácitos e/ou explícitos é denominado de "conversão do conhecimento". Takeuchi e Nonaka (2008) descrevem, por meio do Modelo SECI, quatro modos de conversão do conhecimento: (i) socialização consiste em compartilhar e criar conhecimento tácito por meio de experiência direta; (ii) externalização - articula o conhecimento tácito por meio do diálogo e da reflexão; (iii) combinação - ocorre quando o indivíduo sistematiza e aplica a informação e o 
conhecimento explícito; e (iv) internalização - significa aprender e adquirir conhecimento tácito pela prática. O compartilhamento de informação e de conhecimento constitui um primeiro passo em direção à construção do conhecimento, é preciso também combinar, sistematizar e aplicar, na prática, o conhecimento recebido para levar à sua apropriação.

\section{Passos Metodológicos}

A presente pesquisa caracteriza-se como um estudo exploratório, por analisar as necessidades e os desafios relacionados a um público específico, pouco tratado na literatura da área relacionada. Os objetivos deste trabalho determinaram os seguintes passos metodológicos: Estudo etnográfico - com análise qualitativa para direcionar o levantamento dos requisitos necessários à comunicação, à coordenação, à cooperação e à construção do conhecimento em uma $\mathrm{CoP}$ envolvendo surdos e não-surdos. Elaboração do framework conceitual - levantamento, integração e adaptação de modelos de colaboração, de CoPs e de construção do conhecimento. Os modelos, juntamente com os requisitos de acessibilidade identificados no passo anterior deram suporte à criação do FC_InCoP, framework de apoio ao design de ambientes virtuais, de suporte às CoPs inclusivas pelo prisma "usuários surdos e não-surdos". Aplicação do framework conceitual - aplicação do FC_InCoP no desenvolvimento de uma ferramenta para videoconferência. A ferramenta foi aplicada junto à comunidade surda, simultaneamente sujeito e colaboradora da pesquisa.

\section{Estudo Etnográfico}

O estudo etnográfico foi realizado para investigar as necessidades inerentes à colaboração no contexto de hipótese, um ambiente misto, envolvendo surdos e não-surdos. Para tanto, uma Cop foi criada e cultivada por meio de reuniões colaborativas, de maneira a fornecer um ambiente de interação que permitisse aos seus participantes colaborarem em prol de um objetivo comum: "a construção do conhecimento sobre a fonologia da Libras". O ambiente de colaboração foi frequentado por alunos surdos do curso de Graduação Letras Libras, um intérprete ouvinte e os co-autores desta pesquisa. O intérprete de Libras teve papel essencial no processo, não só por intermediar a comunicação, mas, também, por estimular os participantes a compartilhar conhecimento.

As reuniões colaborativas foram gravadas para facilitar a análise, que versou sobre os seguintes eixos: organização conversacional e princípios de cooperação; elementos influenciadores na construção do conhecimento. Para cada eixo definido foi possível mapear o resultado da análise com a sua respectiva implicação em um ambiente virtual colaborativo inclusivo aos surdos. As ações executadas durante as reuniões foram agrupadas de acordo com os seus objetivos na colaboração para permitir o cruzamento de sua ocorrência com os parâmetros analisados.

\subsection{Organização Conversacional e Princípios de Cooperação}

Segundo de Souza (2005) a intenção do usuário e os efeitos resultantes do uso da linguagem têm um considerável grau de relevância para a comunicação. Myers (2002) ressalta que a análise da conversação ajuda a perceber como os participantes utilizam a linguagem para organizar a interação de momento a momento. Nesta perspectiva, buscouse, com o apoio da semiótica e da etnometodologia, identificar a ação da linguagem no auxílio à comunicação e à coordenação nas reuniões colaborativas. 
Algumas das teorias clássicas que embasaram principalmente esta análise foram: Etnometodologia (Garfinkel, 1967), Análise da Conversação (Sacks, Schegloff e Jefferson, 1974); e Princípios de Cooperação (Grice, 1975). No Quadro 2 são apresentadas as implicações dos aspectos de Organização Conversacional e Princípios de Cooperação para os Ambientes Virtuais Colaborativos Inclusivos (AVCI).

Quadro 2. Organização Conversacional,Princípios de Cooperação - implicações para AVCI

\begin{tabular}{|c|c|}
\hline & Implicações para AVCI \\
\hline \multirow{3}{*}{ 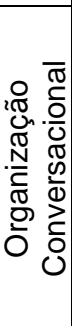 } & $\begin{array}{l}\text { Os ambientes criados para dar suporte às CoPs, embasadas fortemente pela execução de tarefa, } \\
\text { desencadeiam um proeminente uso de perguntas e respostas (ação e reação), o que minimiza } \\
\text { as dificuldades de organização de turnos e de sequências interativas neste tipo de ambiente. }\end{array}$ \\
\hline & $\begin{array}{l}\text { O estabelecimento e a formalização de protocolos sociais podem ser úteis em ambientes virtuais } \\
\text { para organizar a comunicação (turnos e sequências) e o processo de correção em interações } \\
\text { síncronas. }\end{array}$ \\
\hline & $\begin{array}{l}\text { Agentes conversacionais podem ser usados para sinalizar as ações correntes (para indicar } \\
\text { quando o falante corrente completou o seu turno), apontar as próximas ações, monitorar as } \\
\text { tarefas; apontar dicas, auxiliar na resolução de problemas, dentre outros. }\end{array}$ \\
\hline \multirow{3}{*}{ 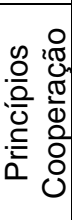 } & $\begin{array}{l}\text { Mediadores devem direcionar a fala ao intérprete, mas, de forma que a passagem da vez seja } \\
\text { percebida por todo o grupo. É preciso utilizar mecanismos de percepção, que situem o foco da } \\
\text { exibição do contexto no ator corrente. }\end{array}$ \\
\hline & idades pode apoiar o alcance dos objetivos em AVCI. \\
\hline & de apoio à tc \\
\hline
\end{tabular}

\subsection{Elementos Influenciadores na Construção do Conhecimento}

Com o apoio do modelo SECI, foi realizada uma análise para identificar, nas ações executadas nas reuniões, a ocorrência dos processos de conversão do conhecimento e também as implicações dessas ações para Ambientes Virtuais Colaborativos Inclusivos (AVCI). O Quadro 3 apresenta o resultado desta análise.

\section{Quadro 3. A Construção do Conhecimento e as implicações para AVCI}

\begin{tabular}{|l|l|l|}
\hline Processo / Ações na CoP & \multicolumn{1}{|c|}{ Modelo SECI } & \multicolumn{1}{|c|}{ Implicações para AVCI } \\
\hline $\begin{array}{l}\text { Coleta/Troca de } \\
\text { experiências sobre a Libras } \\
\text { e a cultura surda. }\end{array}$ & $\begin{array}{l}\text { Experiência direta, } \\
\text { Socialização }\end{array}$ & $\begin{array}{l}\text { Ferramentas para a comunicação entre os } \\
\text { diferentes perfis de atores e de apoio } \\
\text { lingüístico (dicionários, tradutores). }\end{array}$ \\
\hline $\begin{array}{l}\text { Armazenamento/Registro e e } \\
\text { gravação dos sinais em } \\
\text { Libras e de seus } \\
\text { parâmetros. }\end{array}$ & $\begin{array}{l}\text { Transferência e } \\
\text { armazenamento dos } \\
\text { conhecimentos tácito e } \\
\text { explícito, Socialização e } \\
\text { Combinação }\end{array}$ & $\begin{array}{l}\text { Registro da informação trocada e dos } \\
\text { resultados das Interações (exs.:resultado } \\
\text { de discussões, de uma tarefa). }\end{array}$ \\
\hline $\begin{array}{l}\text { Disseminação/Explicação } \\
\text { sobre os objetivos da } \\
\text { pesquisa e o Modelo } \\
\text { Fonológico de Libras (MFL). }\end{array}$ & $\begin{array}{l}\text { Conhecimento tácito é } \\
\text { articulado, Externalização }\end{array}$ & $\begin{array}{l}\text { Utilizar formas de apresentação da } \\
\text { informação adequada aos surdos (vídeo, } \\
\text { escrita de sinais), além daquelas próprias } \\
\text { dos não-surdos. }\end{array}$ \\
\hline $\begin{array}{l}\text { Análise e Uso/ Tradução } \\
\text { da Informação; Identificação } \\
\text { de sinais em Libras para } \\
\text { cada parâmetro do MFL; } \\
\begin{array}{l}\text { Consulta aos vídeos para a } \\
\text { descrição de cada sinal } \\
\text { identificado. }\end{array}\end{array}$ & $\begin{array}{l}\text { Conhecimentos explícito e } \\
\text { tácito são, sistematizados, } \\
\text { articulados e aplicados, } \\
\text { Externalização, } \\
\text { Combinação e } \\
\text { Internalização }\end{array}$ & $\begin{array}{l}\text { Exibição adequada do falante corrente para } \\
\text { permitir e facilitar a percepção, pelo } \\
\text { intérprete, para possibilitar a tradução e a } \\
\text { intervenção quando necessária; Adequada } \\
\text { exibição do intérprete para permitir aos } \\
\text { surdos a compreensão das mensagens. }\end{array}$ \\
\hline
\end{tabular}

Nesta análise, foram identificados alguns processos cooperativos presentes na conversação e a ação da linguagem nas interações, na forma como os participantes orientavam as suas ações e como organizavam uma conversa. As interações ocorreram de forma mais espontânea, com pouco formalismo, porém, com o estabelecimento de alguns papéis e funções no processo de colaboração. Alguns marcadores foram relevantes para a organização de turnos e de sequências, como, o olhar, a pausa e o fecho de um enunciado. 


\section{Framework Conceitual Proposto : FC_InCoP}

O framework proposto no presente trabalho tem como objetivo apoiar o design de ambientes computacionais virtuais colaborativos de suporte à CoPs envolvendo surdos, não-surdos e intérpretes. Apresenta-se, desta forma, um esquema conceitual que considera os elementos necessários ao acesso e a garantia de participação de pessoas surdas neste tipo de ambiente de colaboração. A partir do modelo base (ontologia de Tifous et al., 2007) e das novas variáveis identificadas no estudo etnográfico foi proposto o modelo preliminar do FC_InCoP (Figura 1). As variáveis incorporadas ao modelo base foram destacadas em verde claro e são discutidas na sequência:

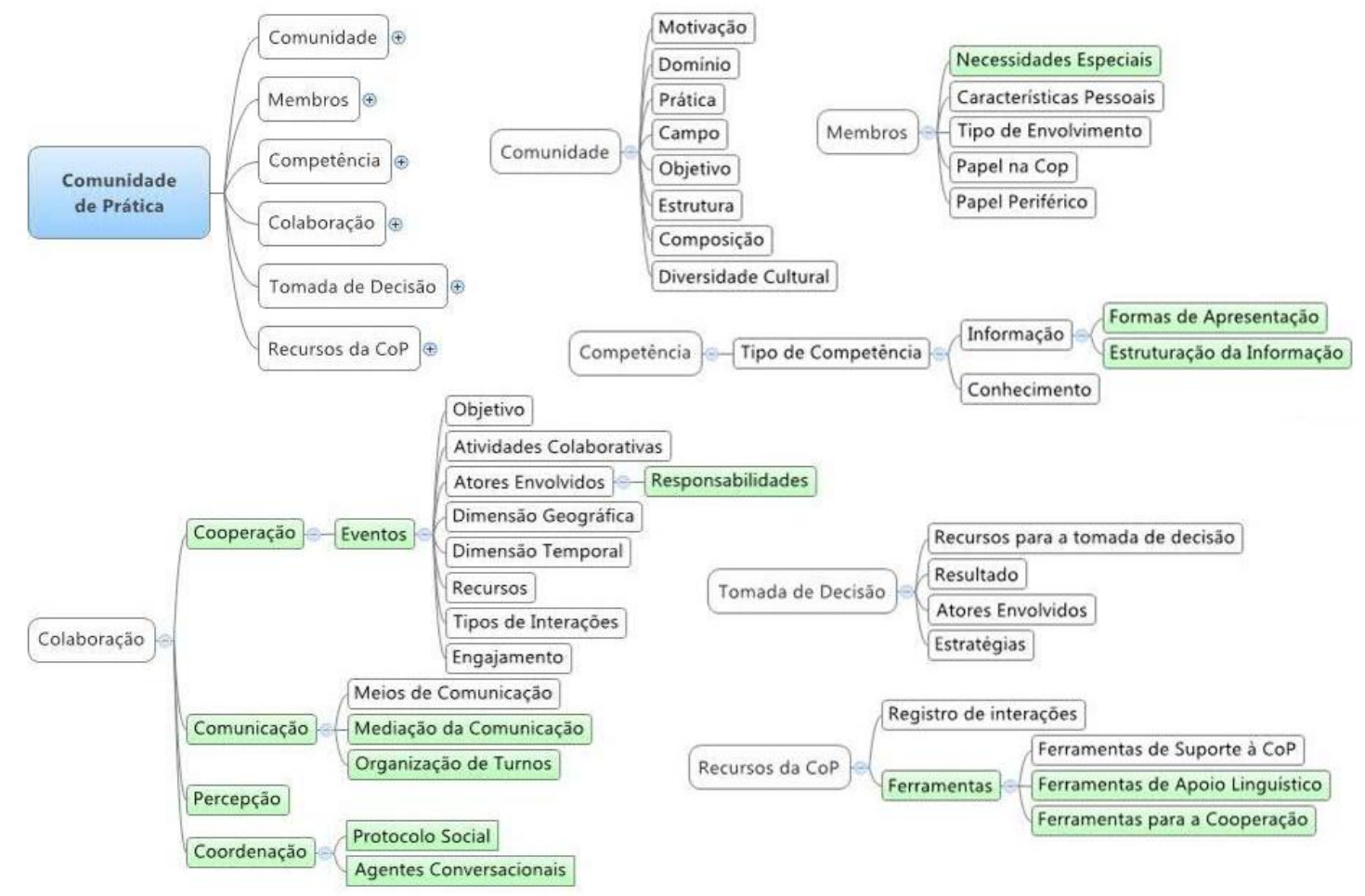

Figura 1. Modelo Preliminar do FC_InCoP

Necessidades Especiais: Os membros de uma comunidade podem apresentar necessidades especiais que devem ser adequadamente atendidas. Na hipótese do nosso trabalho, elas se referem às necessidades associadas ao caráter inclusivo dos ambientes em relação à cultura surda. Formas de Apresentação: É preciso caracterizar as formas de registro da informação que, no caso de hipótese devem incluir: vídeos em Libras, escrita de sinais, imagens e símbolos, entre outros. Estruturação da Informação: A estruturação e a organização da informação, objeto da CoP, podem facilitar a busca e a aquisição de conhecimento.

Eventos: A colaboração envolve a organização de eventos que podem incluir um grupo específico, dependendo do contexto e das necessidades do ambiente. Responsabilidades: Face à diferenciação de perfis, em que os participantes podem assumir papéis estratégicos em um ambiente de colaboração, é preciso também considerar que esses papéis implicam em responsabilidades, que determinam a forma como a comunidade é coordenada. Mediação da Comunicação: No ambiente de hipótese, observa-se a necessidade da participação ativa de Intérprete para garantir a comunicação 
entre surdos e não-surdos. Organização de Turnos: Para sustentar a conversação entre surdos e não-surdos é importante utilizar mecanismos de "Organização de Turnos", para apoiar a troca de turnos, a organização de sequências conversacionais, a resolução de problemas de sobreposição da fala, dentre outros.

Protocolo Social: é significativo em ambientes colaborativos, como o do caso de hipótese, o estabelecimento de protocolo social para que os participantes possam organizar e coordenar as suas ações (contrapondo os sistemas rígidos e formais de coordenação). Agentes Conversacionais: É um mecanismo que pode ser usado para auxiliar no processo de comunicação, diagnosticando as ações e interagindo com o usuário. Os agentes conversacionais podem ser utilizados como sinalizadores na organização dos turnos de fala. Ferramentas de apoio Lingüístico: Inclui as ferramentas que podem apoiar a comunicação face às necessidades da comunidade surda: dicionários, tradutores, sistemas de transcrição, dentre outros. Ferramentas para a Cooperação: A cooperação pode envolver o trabalho conjunto sobre um documento, o que determina o uso de ferramentas como, editores cooperativos e sistemas de controle de versões de documentos.

O modelo preliminar é proposto como meio para facilitar a representação do conhecimento a respeito de CoPs. A partir do modelo preliminar foram derivados os modelos comportamentais e estruturais do FC_InCoP.

\subsection{Modelos Comportamentais}

Seguindo a abordagem de Martins (2009), que propõe o reuso do conhecimento de ontologias, foi possível derivar os modelos comportamentais e estruturais do FC_InCoP. Assim, a partir do modelo preliminar foi capturado o conhecimento a respeito das tarefas e dos papéis envolvidos na realização de cada tarefa, por meio de: (i) identificação das tarefas e decomposição das subtarefas a partir do modelo preliminar; (ii) identificação dos papéis envolvidos na realização de cada tarefa. As tarefas e subtarefas indicam as possíveis funcionalidades que uma aplicação deve realizar e, assim, são candidatas a casos de uso do sistema. Desta forma, foram identificados os casos de uso e foram derivados os outros modelos comportamentais.

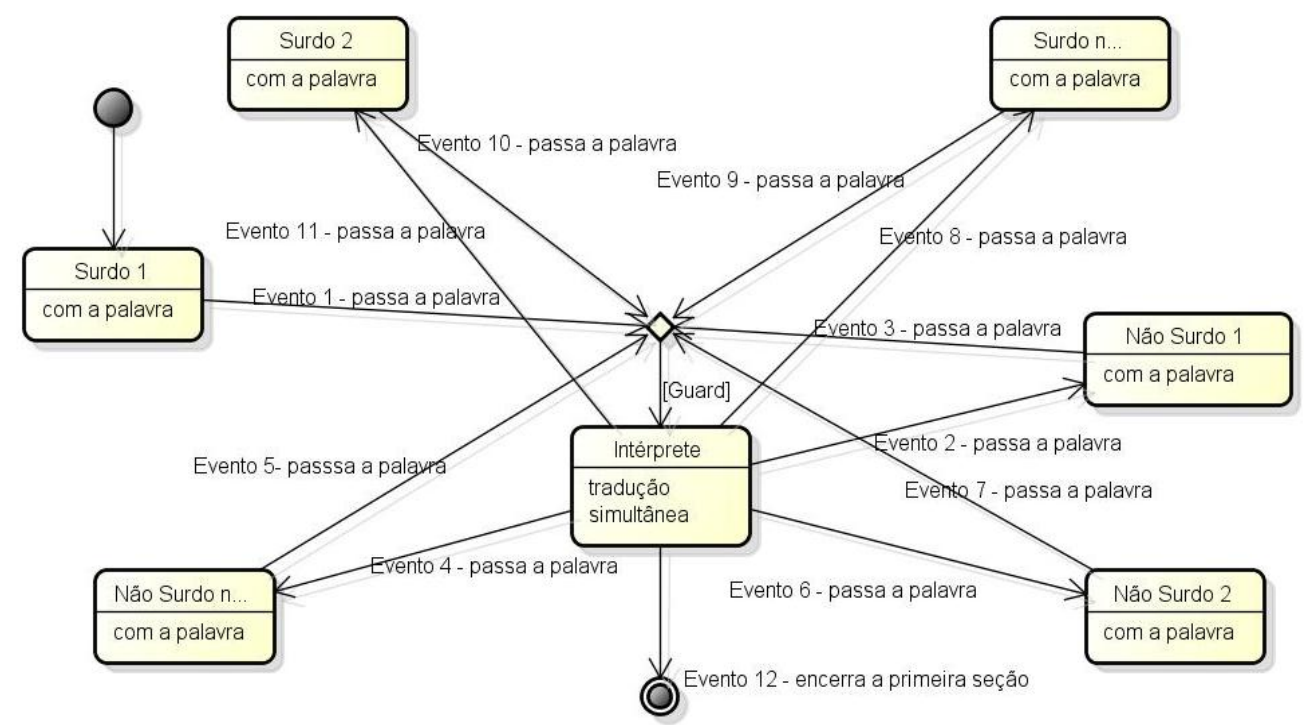

Figura 2. Diagrama de Estados - Exemplo de troca de turnos "Fala um por vez" 
É apresentado na Figura 2 um diagrama relativo a uma comunicação síncrona entre surdos e não-surdos. Este tipo de comunicação traz algumas implicações ao ambiente, como a necessidade de um intérprete para mediar à comunicação. No exemplo apresentado na Figura 2, é enfatizado o comportamento de "troca de posse da palavra" e é mostrada uma seção de conversação, em que cada membro fala apenas uma vez e o intérprete faz a tradução de cada fala. É possível também observar que a troca de turnos segue a regra básica de organização da conversação em que os falantes se alternam, um espera o outro concluir a sua fala e todos têm acesso à palavra.

A passagem de turno, neste caso, pode ser delimitada por um marcador linguístico ou paralinguístico (pausas, hesitações, movimento da mão). Após a tradução do intérprete, que marca a transição de um turno, o próximo falante obtém o turno pela auto-escolha.

\subsection{Aplicação do FC_InCoP}

Com o intuito de verificar a sua aplicabilidade, o FC_InCoP apoiou o desenvolvimento de uma ferramenta para Videoconferência, que considera os aspectos mais significativos e críticos para promover a interação entre surdos e não-surdos. Esta ferramenta fornece um espaço adequado para a comunicação e colaboração em uma CoP, por permitir a interação entre pessoas, independentemente de sua localização geográfica. Portanto, a partir dos elementos necessários à inclusão do surdo, que compõem o FC_InCoP, foram definidos os requisitos para o projeto e desenvolvimento da ferramenta.

Um experimento foi efetuado, no qual a ferramenta instrumentou a realização de uma reunião por videoconferência, que teve como objetivo promover a interação entre os participantes para a construção de um artigo sobre um tema de interesse do grupo: "as dificuldades que o surdo encontra no seu dia a dia". Participaram da reunião: três surdos, um intérprete e dois não-surdos, dispersos geograficamente. A metodologia que orientou a avaliação da ferramenta contemplou os seguintes passos: identificação das variáveis relevantes e dificuldades apresentadas durante a reunião; e verificação, por meio de observação direta e análise dos documentos disponibilizados durante a realização da videoconferência, da ocorrência dos processos de conversão do conhecimento.

Algumas implicações foram identificadas durante a reunião, como: o desvio de foco por parte de alguns participantes; a necessidade dos surdos em obter um marcador gestual para indicar que o ouvinte compreendeu a sua fala (além da tradução do intérprete); a necessidade de bloquear os outros participantes quando havia um "falante corrente" (neste caso, enquanto o "falante corrente" fazia a sua comunicação com a tradução simultânea do intérprete os outros participantes surdos desenvolviam conversas paralelas).

Com relação aos processos de conversão do conhecimento, verificou-se que: (i) a Socialização ocorreu pela manifestação dos participantes surdos, na exposição de suas dificuldades enfrentadas no dia a dia e também nos momentos em que houve a troca de experiências com relação às culturas do não-surdo e do surdo; (ii) a Externalização aconteceu, principalmente, na articulação das informações e conceitos necessários à realização da videoconferência (instruções sobre a ferramenta, responsabilidades de cada participante e protocolo para a conversação) apresentados na tela inicial da ferramenta por meio de vídeo em Libras com legenda em português; (iii) o processo de Combinação ocorreu fortemente durante a elaboração dos relatos pela troca de informação, pela análise de documentos, pela classificação, acréscimo e categorização da informação; e (iv) 
durante as reuniões foi possível sentir o realismo e a essência das experiências compartilhadas, traduzidas na forma de um relato escrito em Português (sob a ótica de um não-surdo) e sinalizado em Libras (sob a ótica de um surdo). Esta reflexão em torno da problematização levantada permitiu a geração de relatos que respeitassem as formas de compreensão e de expressão dos participantes envolvidos, o que sugere a ocorrência da Internalização.

Como resultado das análises efetuadas, observou-se que mesmo em face às dificuldades inicialmente encontradas foi possível alcançar o objetivo da reunião: os participantes surdos e não-surdos puderam interagir de maneira profícua com a medição do intérprete e o artigo foi construído a partir das discussões realizadas durante a reunião. Entretanto, novos testes devem ser realizados a fim de comprovar os resultados inicialmente obtidos.

\section{Conclusões}

Considerando as especificidades das comunidades surdas, pretende-se com o presente trabalho, auxiliar no desenvolvimento de ambientes virtuais colaborativos acessíveis e inclusivos de suporte a CoPs que proporcione oportunidades iguais, nas diversas áreas, às pessoas surdas. A presente pesquisa oferece algumas contribuições:

Com a realização do estudo etnográfico e desenvolvimento do framework foram identificados os principais aspectos envolvidos na colaboração entre surdos e não-surdos. Verificou-se que para cultivar este tipo de CoP é preciso, principalmente, oferecer, entre outras coisas, ferramentas de apoio lingüístico para apoiar a comunicação (dicionários, tradutores, sistemas de transcrição); intérprete para a mediação da comunicação; várias formas de apresentação da informação (vídeos em Libras, escrita de sinais - signwriting); mecanismos de percepção; suporte ao estabelecimento de papéis e responsabilidades como forma de viabilizar a colaboração; mecanismos que permitam a estruturação da informação para auxiliar na busca pela informação e na construção do conhecimento; mecanismos de coordenação, como o uso de protocolos sociais e de agentes conversacionais para orientar a comunicação.

Pretende-se como trabalhos futuros, aplicar o FC_InCoP no desenvolvimento de outras ferramentas e aprofundar os estudos a fim de verificar, pela ótica de grupos da comunidade surda, novos potenciais e limitações do modelo proposto.

\section{Agradecimento}

Agradecemos à Fundação Araucária pelo apoio a esta pesquisa.

\section{Referências}

Almeida, L. D. A., Baranauskas, M. C. C. (2008) Um Prospecto de Sistemas Colaborativos: Modelos e Frameworks. In: VIII Simpósio sobre Fatores Humanos em Sistemas Computacionais IHC 2008, Porto Alegre.

Carroll, J. M., Choo, C. W., Dunlap, D. R., Isenhour, P. L., Kerr, S. T., Maclean, A., Rosson, M. B. (2003) Knowledge management support for teachers. Educational Technology Research and Development, 51(4), p. 42-64.

De Souza, C. S. (2005) The semiotic engineering of human - computer interaction. Cambridge, Mass: The MIT Press. 
Deaudelin, C., Nault, T. (2003) Collaborer pour apprendre et faire apprendre - La place des outils technologiques, Presses de l'Université du Québec.

Fernandes, S. (2006) Avaliação em Língua Portuguesa para Alunos Surdos: Algumas considerações. SEED/SUED/DEE, Curitiba.

Garfinkel, H. (1967) Studies in ethnomethodology. Englewood Cliffs, NJ: Prentice-Hall.

Grice, H. P. (1975) Logic and conversation. In: Cole, P, Morgan, J. (Eds.) Syntax and Semantics, New York: Academic Press, v.3: Speech Acts.

Henri, F. (2006) Communities of Practice: Social Structures for the Development of Knowledge. PALETTE Kick off Meeting, Lausanne.

Langelier, L., Wenger, E. (eds) (2005). Work, Learning and Networked, Québec, Cefrio.

Lave, J., Wenger, E. (1991) Situated learning: Legitimate peripheral participation. Cambridge, UK: Cambridge University Press.

Mantoan, M.T.E. (2005) Inclusão é o Privilégio de Conviver com as Diferenças. In Nova Escola, maio.

Martins, A. F. (2009) Construção de Ontologias de Tarefas e sua Reutilização na Engenharia de Requisitos. Tese de Mestrado, Espírito Santo: UFES.

Miller, G. A. (1995) WordNet: a lexical database for English, Commun. ACM 38(11), p. 39-41.

Myers, G. (2002) Análise da Conversação e da Fala, In Bauer, Martin W. \& GASKELL, George (org.). Pesquisa Qualitativa com Texto, Imagem e Som: Um Manual Prático. Petrópolis: Vozes.

Natalli E. L., Menezes, C. S. (2012) FrameColab: Um framework para a criação de Ambientes Colaborativos In: $23^{\circ}$ Simpósio Brasileiro de Informática na Educação, 2012, Rio de Janeiro.

Quadros, R. M.,Perlin, G.(2007) Estudos surdos II. Petrópolis, RJ: Arara Azul, 2007.

Sacks, H., Schegloff, E. A., Jefferson, G. (1974) A simplest systematics for the organization of turn-taking for conversation. Language, pp. 696-735.

Santana, R.C.G., Santos, P.L.V. A. C. (2002) Transferência da Informação: análise para valoração de unidades de conhecimento. Datagramazero, v.3, n.2.

Takeuchi, H. E Nonaka, I. (2008) Criação e dialética do conhecimento. Gestão do conhecimento. Porto Alegre: Bookman.

Tifous, A., Ghali, A.E., Dieng-Kuntz, R., Giboin, A., Evangelou, C., Vidou, G. (2007) An ontology for supporting communities of practice. In K-CAP 39-4.

Vidou, G., Dieng-Kuntz, R., El Ghali, A., Evangelou, C., Giboin, A., Tifous, A. and Jacquemart, S. (2006) Towards an Ontology for Knowledge Management in Communities of Practice. PAKM'06, p. 303-314.

Weiseth, P. E., Munkvold, B. E., Tvedte, B., Larsen, S. (2006) The Wheel of Collaboration Tools: A Typology for Analysis within a Holistic Framework. CSCW'2006, Banff, Canada, p. 239-248.

Wenger, E. (2004) Knowledge Management as a Doughnut: Shaping your knowledge strategy through communities of practice. Ivey Business Journal, 68(3).

Wenger, E., Trayner, B., and Laat, M. (2011). Promoting and assessing value creation in communities and networks: A conceptual framework. The Netherlands: Ruud de Moor Centrum.

Schneider, E. I., Medeiros, L.F., Moser, A.(2012) A aprendizagem situada nas comunidades de prática: Uma aproximação fenomenológica. In: Anais do $23^{\circ}$ Simpósio Brasileiro de Informática na Educação, 2012, Rio de Janeiro. 